\title{
Efficacy of Dietary Arachidonic Acid Provided as Triglyceride or Phospholipid as Substrates for Brain Arachidonic Acid Accretion in Baboon Neonates
}

\author{
VASUKI WIJENDRAN, MENG-CHUAN HUANG, GUAN-YEU DIAU, GÜNTHER BOEHM, \\ PETER W. NATHANIELSZ, J. THOMAS BRENNA \\ Division of Nutritional Sciences [V.W., M.-C.H., G.-Y.D., J.T.B.] and Laboratory for Pregnancy and \\ Newborn Research [P.W.N.], Cornell University, Ithaca, NY, U.S.A.; NUMICO Research Group, \\ Friedrichsdorf, Germany [G.B.]
}

\begin{abstract}
Arachidonic acid (AA) is a long-chain polyunsaturate (LCP) present in human breast milk as both triglyceride (TG) and as phospholipid (PL). There has been little attention to the metabolic consequences of lipid form of AA in infant formulas. Our objective was to investigate the efficacy of dietary TG and PL as carriers of AA for accretion in the brain and associated organs of term baboon neonates consuming a formula with LCP composition typical of human milk. TG and phosphatidylcholine (PC) with $\left[\mathrm{U}-{ }^{13} \mathrm{C}\right]-\mathrm{AA}$ in the sn-2 position and with unlabeled 16:0 in the remaining positions (TG-AA* or PL-AA*, respectively) were used as tracers to study the tissue $\mathrm{AA}^{*}$ incorporation. Baboon neonates received a single oral dose of either TG-AA* $(n=3)$ or PL-AA* $(n=4)$ at $18-19 \mathrm{~d}$ of life. Tissues were obtained $10 \mathrm{~d}$ later (28-29 d of life) and isotopic enrichment was measured. In the brain, $4.5 \%$ of the PL-AA* dose and $2.1 \%$ of the TG-AA* dose were recovered as brain $\mathrm{AA}^{*}$, respectively, indicating that PL was about 2.1-fold more effective than TG as a substrate for brain AA accretion. Preferential incorporation of PL-derived $\mathrm{AA}^{*}$ over TG source of $\mathrm{AA}^{*}$ was also observed in the liver, lung, plasma, and erythrocytes. Because of the quantitative predominance of TG-AA in formula, total brain AA accretion, expressed as absolute weight, was 5.0-fold greater from TG-AA than from PL-AA. We estimate that about half of postnatal brain AA accretion is derived from dietary preformed AA in term baboon
\end{abstract}

\section{ABSTRACT}

neonates consuming a formula with lipid composition similar to that of human milk. (Pediatr Res 51: 265-272, 2002)
$\mathbf{A A}$, arachidonic acid

\section{Abbreviations}
$\mathbf{A A}^{*},\left[{ }^{13} \mathrm{C}\right]$ arachidonic acid
DHA, docosahexaenoic acid
LA, linoleic acid
TG, triglyceride
PL, phospholipid
PC, phosphatidylcholine
TG-AA*, triglyceride containing $\left[{ }^{13} \mathrm{C}\right]$ arachidonic acid in the sn-2 position
PL-AA*, phosphatidylcholine containing $\left[{ }^{13} \mathrm{C}\right]$ arachidonic acid in the sn-2 position
TG-AA, dietary arachidonic acid provided as triglyceride
PL-AA, dietary arachidonic acid provided as phospholipid
LCP, long-chain polyunsaturated fatty acids
RPE, retinal pigment epithelium
CS, cesarean section
dGa, days of gestational age
FAME, fatty acid methyl esters
GC-FID, gas chromatography with flame ionization detector GCC-IRMS, gas chromatography-combustion isotope ratio mass spectrometry

AA (20:4n-6) is the predominant polyunsaturated fatty acid (PUFA) in mammalian brain and neural tissues $(1,2)$. As major

Received March 29, 2001; accepted September 6, 2001

Correspondence: J. Thomas Brenna, Cornell University, Savage Hall, Ithaca, NY 14853, U.S.A., e-mail: jtb4@cornell.edu

This work was supported by Numico Research Group Germany. The doses for this study were kindly provided by F. Hoffmann-La Roche AG, Basel, Switzerland. components of structural phospholipids, AA is critical for membrane function $(3,4)$ and serves as a precursor for eicosanoids, which play important roles in cell division $(5,6)$ and signal

Present addresses: Vasuki Wijendran, Brandeis University, Foster Biomedical Laboratory, Waltham, MA; Meng-Chuan Huang, Kaohsiung Medical University, School of Medicine, Department of Public Health, Kaohsiung, Taiwan. 
transduction $(7,8)$ and many other physiologic processes. Several studies implicate dietary AA as a critical factor for growth in preterm and term human infants $(9-12)$. AA also serves as a precursor for adrenic acid (22:4n-6), which is the third most abundant PUFA in the brain and may be essential for myelin development during the early postnatal period in infants $(13,14)$.

Compared with other stages of the life cycle, the LCP $\left(\mathrm{C}_{\mathrm{n}}, \mathrm{n}>18\right)$ AA and DHA (22:6n-3) rapidly accumulate in the brain during its development $(1,15)$, which is greatest starting at the beginning of the third trimester of gestation up to about $2 \mathrm{y}$ of age in humans $(16,17)$. Human milk contains AA and DHA $(18,19)$, whereas formulas in North America do not provide these preformed LCP, although LCP are available in many countries in Europe, Asia, and South America. Although preterm and term infants can synthesize AA and DHA from their precursors LA (18:2n-6) and linolenic (LNA; 18:3n-3) acids, respectively $(20,21)$, there is increasing evidence that a dietary supply of preformed LCP is conditionally essential for preterm and term infants (22-25). The composition, molecular structure, and source of LCP in the diet all influence LCP uptake and accumulation in tissues.

The roles of LCP composition (26-29) and molecular structure (30-33) in absorption and tissue accretion are well documented. In general, preformed LCP are more efficiently incorporated into tissues than LCP derived from their $\mathrm{C} 18$ precursors, and the n-3 and n-6 families each influence incorporation of the other (34-36). However, the major dietary form of fatty acids is as acyl esters, either TG or PL. In human breast milk, TG carry $98 \%$ of all fatty acids with the remainder in PL (19). However, LCP are more highly concentrated in PL, so that PL carries $5 \%-15 \%$ of LCP to the infant with the remainder in TG (37). Its form in source materials, which are typically single-cell organisms or egg lecithin, has normally dictated the lipid class carrying AA in infant formulas.

$\mathrm{PL}$ as a carrier of AA is reported to be absorbed at least as efficiently as human breast milk AA and as formula AA provided primarily in the form of TG in preterm infants (38, 39). Dietary TG and PL derived PUFA were differently distributed into lipoprotein lipids and transported to target organs in rats (40) and in adult humans $(41,42)$. Lagarde et al. (42) provided evidence for higher bioavailability of DHA provided as PL compared with TG for incorporation into erythrocytes in human adults. Further, preterm infants fed a formula supplemented with LCP in the form of PL but with significantly lower LCP concentrations than human milk developed similar LCP composition in plasma and erythrocytes as human milk-fed infants, suggesting that the PL source of LCP was more efficiently incorporated (43). However, there are no direct measurements of the bioavailability of dietary TG and PL as sources of LCP for brain accretion in primate neonates.

The objectives of this study were to compare the efficacy of dietary TG and PL as carriers of AA for AA accretion in the brain and associated organs of term baboon neonates and to estimate the contribution of dietary preformed AA to postnatal brain $\mathrm{AA}$ accumulation in primate neonates using ${ }^{13} \mathrm{C}$-labeled AA and high-precision isotope ratio mass spectrometry. In the baboon, the brain growth spurt peaks only few weeks before term birth (17) and adequate n-6 and n-3 LCP supply is most important in the immediate neonatal period to support rapid brain development. Thus, brain AA accumulation in baboon neonates at 4 wk postnatal age reported in this study reflects human brain AA accretion during the critical postnatal period.

\section{METHODS}

Animals and diet. The Cornell Institutional Animal Care and Use Committee approved the care of animals and the American Association for Laboratory Animal Care approved the facility. Seven female pregnant baboons (Papio cynocephalus) obtained from the Southwest Foundation for Biomedical Research (San Antonio, TX, U.S.A.) were used in this study. After confirmation of pregnancy, the baboons were transported to the Laboratory for Pregnancy and Newborn Research at Cornell University, and a complete veterinary examination was performed upon arrival. Pregnant baboons were housed in individual cages in sight of at least one other baboon. The room temperature and humidity were maintained at $24^{\circ} \mathrm{C}$ and $70 \%$ respectively, with a 14-h light and 10-h dark cycle. Adult animals consumed a commercial primate chow.

Neonate baboons were obtained by CS while females were under halothane general anesthesia at estimated conceptual ages of 176 to $178 \mathrm{dGa}$. Animal details are presented in Tables 1 and 2. They were housed initially in an enclosed incubator and transferred to individual cages after about $5 \mathrm{~d}$ of age, in a controlled-access nursery where the temperature and humidity were maintained at $28^{\circ} \mathrm{C}$ and $50 \%$, respectively.

Neonate baboons were fed a formula containing LCP, provided by Numico Research Group (Friedrichsdorf, Germany). The energy, carbohydrate, fat, and protein content of the formula were $67 \mathrm{kcal}, 7.5 \mathrm{~g}, 3.5 \mathrm{~g}$, and $1.4 \mathrm{~g} / 100 \mathrm{~mL}$, respectively. The fatty acid composition of the formula is presented in Table 3. The LCP composition and the n-6:n-3 ratio of 7.5 in the study formula are in the range reported for human breast milk $(18,19)$. Distribution of AA into TG and PL was $92 \%$ and $8 \%$, respectively, which is also within the range reported for human breast milk (37).

Doses and sampling. Doses were chemically synthesized and kindly provided by Roche (Switzerland). The isotopic enrichment in $\left[\mathrm{U}^{13} \mathrm{C}\right]-\mathrm{AA}(\mathrm{AA} *)$ was determined as $97 \%$ by gas chromatography mass spectrometry. The triglyceride tracer (TG-AA*) contained the $\mathrm{AA}^{*}$ in the sn-2 position with unlabeled 16:0 in the sn-1 and sn-3 positions. The phospholipid tracer $\left(\mathrm{PL}-\mathrm{AA} *\right.$ ) was $\mathrm{PC}$ with $\mathrm{AA}^{*}$ in the sn-2 position and

Table 1. Birth weight, weight gain, and organ weights of animals in the study

\begin{tabular}{lcc} 
& TG group* $(n=3)$ & PL group $\dagger(n=4)$ \\
\hline Birth weight $(\mathrm{g})$ & $897 \pm 88$ & $891 \pm 105$ \\
Body weight at death $(\mathrm{g})$ & $1100 \pm 142$ & $1112 \pm 148$ \\
Weight gain $(\mathrm{g})$ & $203 \pm 61$ & $221 \pm 71$ \\
Organ weights $(\mathrm{g})$ & & \\
$\quad$ Brain & $95 \pm 9$ & $103 \pm 13$ \\
Liver & $31.0 \pm 7.7$ & $29.9 \pm 4.7$ \\
Heart & $7.0 \pm 0.4$ & $6.9 \pm 1.4$ \\
Lung & $9.2 \pm 1.0$ & $7.3 \pm 0.5$ \\
\hline
\end{tabular}

Data expressed as mean $\pm \mathrm{SD}$.

* Neonates dosed with TG-AA*.

$\dagger$ Neonates dosed with PL-AA*. 
Table 2. Characteristics of baboon neonates in the study

\begin{tabular}{|c|c|c|c|c|c|}
\hline & $\begin{array}{l}\text { Gestational } \\
\text { age (d) }\end{array}$ & Gender & $\begin{array}{l}\text { Dose amount } \\
(\mathrm{mg})^{*}\end{array}$ & $\begin{array}{l}\text { Age at } \\
\text { dosing } \\
\text { (d) }\end{array}$ & $\begin{array}{l}\text { Age } \\
\text { at } \\
\text { death } \\
\text { (d) }\end{array}$ \\
\hline \multicolumn{6}{|c|}{ TG group $\dagger$} \\
\hline 142 & 176 & $\mathrm{M}$ & 8.6 & 18 & 28 \\
\hline 143 & 178 & M & 10.9 & 18 & 28 \\
\hline 149 & 176 & M & 10.4 & 19 & 29 \\
\hline \multicolumn{6}{|c|}{ PL group } \\
\hline 141 & 176 & M & 14.1 & 19 & 29 \\
\hline 147 & 176 & $\mathrm{~F}$ & 10.1 & 18 & 28 \\
\hline 148 & 176 & M & 9.8 & 19 & 29 \\
\hline 150 & 176 & $\mathrm{~F}$ & 6.7 & 19 & 29 \\
\hline
\end{tabular}

$\mathrm{M}$, male; F, female.

* AA concentration (mg) analyzed in the dose orally administered to the neonates.

$\dagger$ Neonates dosed with TG-AA*.

$\ddagger$ Neonates dosed with PL-AA*.

unlabeled 16:0 in the sn-1 position. Either TG-AA* or PL-AA* tracer was weighed into a tared $10-\mathrm{mL}$ round-bottom flask. Known amount of unlabeled PC (soy lecithin, Sigma Chemical, St. Louis, MO, U.S.A.) and olive oil carriers were added and the mixture was dissolved in $200 \mu \mathrm{L}$ ethanol and vortexed. The amounts of unlabeled PC and olive oil added to the dose mixtures were adjusted such that the total amounts of $\mathrm{PC}$ and TG in both the TG-AA* and PL-AA* doses were equivalent. Ethanol was removed by rotary evaporation under vacuum. Warm reconstituted formula $(2.5 \mathrm{~mL})$ was added to the tracer mixture, vortexed for $30 \mathrm{~s}$, and sonicated for $1 \mathrm{~min}$. A $50-\mu \mathrm{L}$

Table 3. Fatty acid composition of the neonate formula

\begin{tabular}{|c|c|}
\hline Fatty acid & $\begin{array}{c}\text { Total fatty acids } \\
\text { (\%wt) }\end{array}$ \\
\hline \multicolumn{2}{|l|}{ SFA } \\
\hline $14: 0$ & 5.6 \\
\hline $16: 0$ & 24.3 \\
\hline 18:0 & 1.4 \\
\hline $20: 0$ & 0.38 \\
\hline $22: 0$ & 0.38 \\
\hline$\Sigma$ SFA & 32.1 \\
\hline \multicolumn{2}{|l|}{ MUFA } \\
\hline $18: 1$ & 47.0 \\
\hline $20: 1$ & 0.31 \\
\hline$\Sigma$ MUFA & 47.4 \\
\hline \multicolumn{2}{|l|}{ n-6 PUFA } \\
\hline $18: 2$ & 14.0 \\
\hline $\mathrm{g} / 100 \mathrm{~mL}$ & 0.40 \\
\hline $18: 3$ & 0.28 \\
\hline $20: 4$ & 0.55 \\
\hline $\mathrm{mg} / 100 \mathrm{~mL}$ & 15.8 \\
\hline $22: 4$ & 0.25 \\
\hline$\Sigma$ n-6 PUFA & 15.1 \\
\hline \multicolumn{2}{|l|}{ n-3 PUFA } \\
\hline $18: 3$ & 1.6 \\
\hline $\mathrm{g} / 100 \mathrm{~mL}$ & 0.046 \\
\hline $20: 5$ & 0.10 \\
\hline $22: 6$ & 0.30 \\
\hline $\mathrm{mg} / 100 \mathrm{~mL}$ & 8.6 \\
\hline$\Sigma n-3$ PUFA & 2.0 \\
\hline Ratio of n-6:n-3 PUFA & 7.5 \\
\hline
\end{tabular}

SFA, saturated fatty acids; MUFA, monounsaturated fatty acids; PUFA, polyunsaturated fatty acids. sample of the dose was saved for fatty acid analysis. The dose and three rinses with formula were administered orally to the neonates.

Neonate baboons were randomized to receive either a single bolus dose of TG-AA* $(n=3)$ or PL-AA* $(n=4)$. The dose was administered orally to the neonates at $18-19 \mathrm{~d}$ of age (Table 2), just before a morning feed. Neonates were fed as usual immediately after the dosing. The quantities of $\mathrm{AA}^{*}$ in the tracer doses given to the neonates calculated from volumes administered and fatty acid concentration determined by capillary GC-FID are shown in Table 2.

Neonate tissues were obtained $10 \mathrm{~d}$ post dosing (28-29 d of age) when the animals were killed by exsanguination under halothane anesthesia. Tissue, plasma, and erythrocyte samples were collected. Blood was collected with heparin as anticoagulant, and plasma and erythrocytes were separated immediately by centrifugation at $4{ }^{\circ} \mathrm{C}$ and frozen in liquid $\mathrm{N}_{2}$. The brain, liver, lung, and heart tissues were quickly removed, weighed, aliquoted into vials, and immediately frozen in liquid $\mathrm{N}_{2}$. Retina and RPE were collected in saline and immediately frozen in liquid $\mathrm{N}_{2}$. All samples were stored in a $-80^{\circ} \mathrm{C}$ freezer until analysis.

Lipid extraction and analysis. Total lipids were extracted from samples of brain occipital lobe including the visual cortex, right liver lobe, right heart ventricle, right lung, whole retina and RPE, plasma, and erythrocytes by the Bligh and Dyer method (44) and FAME were prepared using $14 \% \mathrm{BF}_{3}$ in methanol. Butylated hydroxytoluene was added to solvents as an antioxidant and a known quantity of freshly prepared heptadecanoic acid in chloroform ( $99+\%$ pure, Sigma Chemical) was added as an internal standard to tissue samples just before extraction. FAME were dissolved in heptane with butylated hydroxytoluene and stored at $-80^{\circ} \mathrm{C}$ until analysis.

FAME were analyzed using a Hewlett Packard 5890 series II GC-FID with a BPX 70 column $(60 \mathrm{~m} \times 0.32 \mathrm{~mm}$ inner diameter $\times 0.25 \mu \mathrm{m}$ film; Hewlett Packard, Palo Alto, CA, U.S.A.) and $\mathrm{H}_{2}$ as carrier gas. Quantitative profiles were calculated using the internal standard and an equal weight FAME mixture to derive response factors for each fatty acid. GC-FID conditions and calibration details have been reported previously (32).

Tracer enrichment analysis was performed using highprecision GCC-IRMS, described in detail previously (45). Briefly, high-precision data are presented as the relative deviation of the sample isotope ratio from the standard Pee Dee Belemnite (PDB) with a ${ }^{13} \mathrm{C} /{ }^{12} \mathrm{C}$ isotope ratio $=\mathrm{R}_{\mathrm{PDB}}=$ 0.0112372 , as:

$$
\delta^{13} \mathrm{C}_{\mathrm{PDB}}=\left(\frac{\mathrm{R}_{\mathrm{X}}-\mathrm{R}_{\mathrm{PDB}}}{\mathrm{R}_{\mathrm{PDB}}}\right) \times 1000=\left(\frac{\mathrm{R}_{\mathrm{X}}}{\mathrm{R}_{\mathrm{PDB}}}-1\right) \times 1000
$$

where $\delta^{13} \mathrm{C}_{\mathrm{PDB}}$ is expressed in permil (\%o) units and $\mathrm{X}$ refers to the sample. $R_{X}$ derived from the above equation was directly converted to atom percent (AP) ${ }^{13} \mathrm{C}$ and atom percent excess (APE) by subtracting the baseline isotope levels.

The absolute mass (grams or mol) of $\mathrm{AA}^{*}$ tracer in the sampled pool was calculated by multiplying APE by the concentration of AA determined by GC-FID. Label is reported 
as percentage of dose (\%Dose) found in a particular pool, the whole organ for instance, to adjust for differing dose sizes. The efficacy of PL-AA* to TG-AA* was estimated by directly comparing the $\%$ Dose of $\mathrm{AA}^{*}$ recovered in the particular pool from the TG and PL sources.

22:4n- $6^{*}$ and $22: 5 n-6^{*}$ synthesis from $\mathrm{AA}^{*}$ were estimated as molar equivalents by adjusting for the number of mol of $\mathrm{C}$ in the tracer and analyte fatty acid. Thus for estimating $22: 4 n-6$ synthesis,

$$
\mathrm{D}_{22: 4 \mathrm{n}-6}=\mathrm{APE}_{22: 4 \mathrm{n}-6} / 100 \times \mathrm{Q}_{22: 4 \mathrm{n}-6} \times 22 / 20
$$

Where, $D$ is dose equivalents and $Q$ is the concentration of 22:4n- 6 determined by GC-FID. Dose equivalents of 22:4 and 22:5n-6 were also expressed as \%Dose. They express the number of mol of tracer $\left(\mathrm{AA}^{*}\right)$ that appear in the products.

Statistics. Group differences were analyzed using the $t$ test and Mann-Whitney test performed by SPSS for Windows 98 (Microsoft, Redmond, WA, U.S.A.), with significance declared at $p \leq 0.05$.

\section{RESULTS}

Neonatal birth weight and organ weights. Birth weight, weight gain, and organ weights are presented in Table 1. Body and organ weights were not significantly different between TG-AA*-dosed and PL-AA*-dosed neonates. Birth weight of the neonates ranged between 776 and $1015 \mathrm{~g}$. Brain and liver weights were about $9 \%$ and $3 \%$ of total body weight, respectively, at 4 wk of age in these neonates.

Fatty acid composition of baboon neonate tissues. Fatty acid composition of brain, retina, RPE, liver, heart, lung, plasma, and erythrocytes of 4-wk-old baboon neonates are shown in Table 4. No statistically significant differences were found in fatty acid composition of tissues between TG-AA*and PL-AA*-dosed neonates. Therefore, they are presented in pooled form. AA was the major PUFA in the brain and RPE, and second only to DHA in retina, consistent with findings in human infants (1). The brain mean AA composition of $9.7 \%$ in neonate baboons in this study compares well with the figure of $11 \%$ reported in human infants (46). 22:4n-6 was present in significant quantities in neural tissues and lung, again in good agreement with human infant data (1). As expected, DHA was the most prevalent n-3 PUFA in neural tissues.

Tracer data: brain, liver, retina, and RPE. The incorporation of $\mathrm{AA}^{*}$ provided as a component of TG (TG-AA*) or PC (PL-AA*) into whole brain, liver, retina and RPE of baboon neonates, presented as \%Dose, is shown in Figure 1, $A$ and $B$. In the brain of neonates, $2.1 \%$ of TG-AA* and $4.5 \%$ of PL-AA* doses were recovered as AA*. From these data, we can calculate that PL-AA* was 2.1 -fold more efficiently incorporated and retained in the brain than TG-AA*. In the liver, accumulation of $\mathrm{AA}^{*}$ from PL-AA* was significantly higher than TG-AA* ( $4.8 \%$ versus $3.1 \%$ of doses, respectively). The

Table 4. Fatty acid composition of neonatal tissues

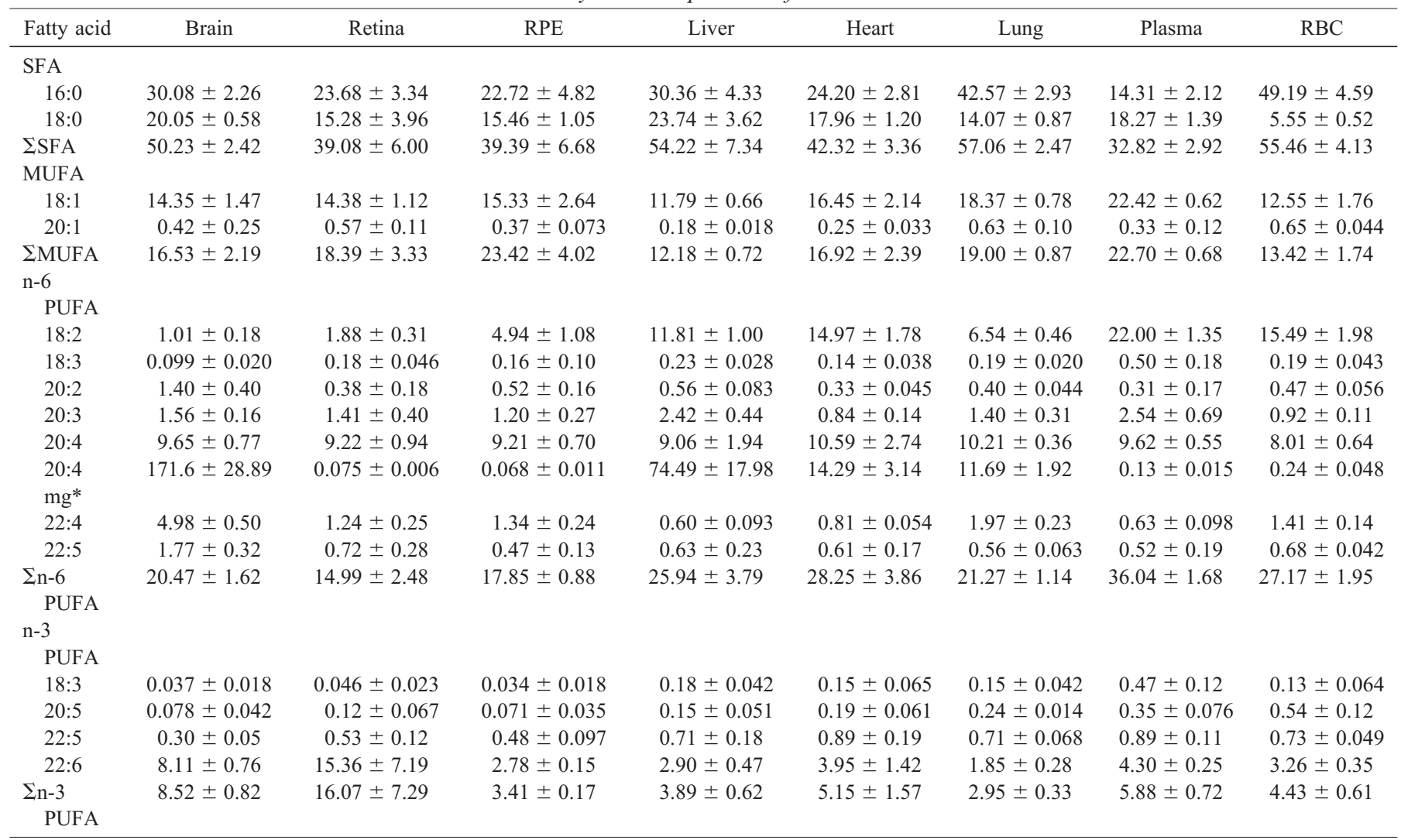

Data expressed as mean $\pm \mathrm{SD}(n=7, \mathrm{wt} \%$ of total fatty acids). SFA, saturated fatty acids; MUFA, monounsaturated fatty acids; PUFA, polyunsaturated fatty acids.

* Milligrams/whole tissue; $\mathrm{mg} / \mathrm{mL}$ plasma, or $\mathrm{mg} / \mathrm{mL}$ erythrocytes. 
ratio of $\mathrm{PL}-\mathrm{AA} *$ to TG-AA* as a substrate for liver AA was 1.6 at $10 \mathrm{~d}$ postdose. Although a similar trend was seen with retina and RPE, incorporation of $\mathrm{AA}^{*}$ as \%Dose in these tissues was not significantly different between PL-AA* and TG-AA*.

Accretion of AA from dietary TG and PL AA (tracees) intake in whole brain, liver, retina, and RPE is presented in Figure 1, $C$ and $D$. In all these tissues, AA derived from dietary TG-AA was higher than from PL-AA. In the brain, AA accumulation per day from dietary TG-AA was $810 \mu \mathrm{g}$, and from PL-AA was $163 \mu \mathrm{g}$ AA intake. The ratio of dietary TG-AA to PL-AA contribution toward brain AA was 5.0. Overall total accumulation of dietary AA in the neonate brain was about 1 $\mathrm{mg} / \mathrm{d}$. At $10 \mathrm{~d}$ postdose, the ratio of dietary TG-AA to PL-AA derived AA was 6.9, 6.3, and 7.5 in the liver, retina, and RPE, respectively.

Tracer data: heart, lung, plasma, and erythrocytes. Figure 2, $A$ and $B$, presents the incorporation of TG-AA* and PL$\mathrm{AA}^{*}$, as \%Dose, in whole heart, lung and per milliliter plasma and erythrocytes. TG-AA* and PL-AA* were incorporated and retained in the heart to a similar extent. In the lung, about 1.7-fold more PL-AA* than TG-AA* was recovered as lung $\mathrm{AA}^{*}$. AA* derived from PL-AA* remained higher than TGAA* in plasma, $(0.0075 \%$ Dose $/ \mathrm{mL}$ versus $0.0045 \%$ Dose $/ \mathrm{mL})$ and in erythrocytes $(0.013 \%$ Dose versus $0.008 \%$ per mL erythrocytes), even $10 \mathrm{~d}$ after dosing.

Dietary AA accumulation in heart lung, plasma, and erythrocytes is shown in Figure 2, $C$ and $D$. In heart, 12.6-fold more formula TG-AA than PL-AA appeared as heart AA. In lung, plasma, and red blood cells, dietary TG-derived AA accretion was about 6.2- to 6.4-fold more than the PL source of AA.
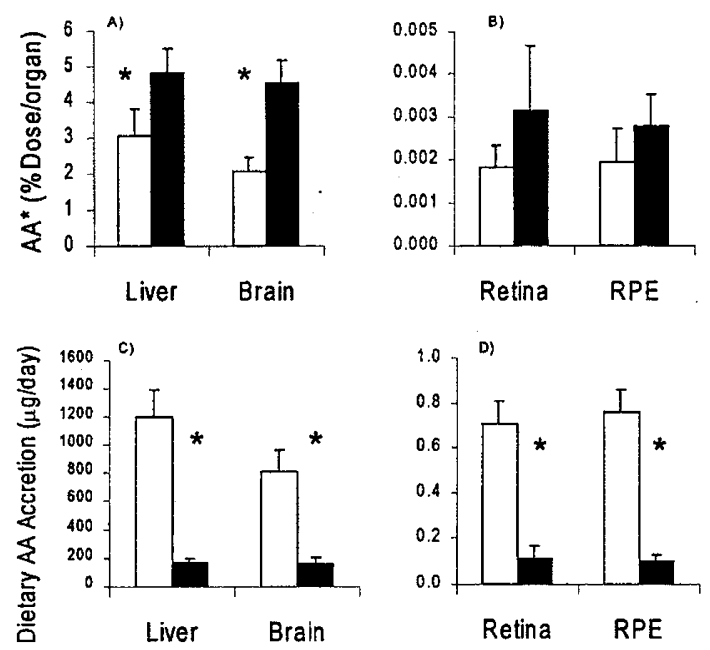

Figure 1. $(A$ and $B)$ Incorporation of $\mathrm{AA}^{*}$ derived from $\mathrm{TG}$ (open bars) and PL sources (solid bars), expressed as \%Dose, in the whole liver, brain, retina, and RPE of neonates. Ratios of PL-AA*- to TG-AA*-derived AA* incorporation into liver, brain, retina, and RPE were $1.6,2.1,1.7$, and 1.4 , respectively. $(C$ and $D$ ) Total dietary AA accretion from TG and PL sources, expressed as micrograms per day per whole tissue, in the neonate liver, brain, retina, and RPE. Ratios of dietary TG-AA to PL-AA accretion in the liver, brain, retina, and RPE were 6.9, 5.0, 6.3, and 7.5, respectively. *Significant differences with $p \leq 0.05 . T G-A A^{*}$, neonates dosed with TG-AA* $(n=3) ; P L-A A^{*}$, neonates dosed with PL-AA* $(n=4)$.
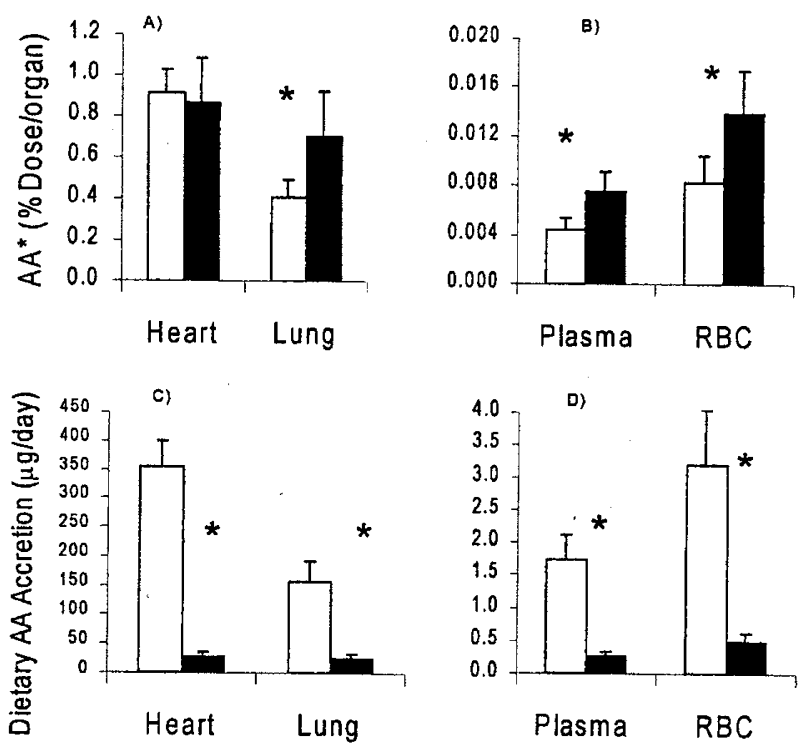

Figure 2. ( $A$ and $B$ ) Incorporation of $\mathrm{AA}^{*}$ derived from TG (open bars) and PL sources (solid bars), expressed as \%Dose, in the whole heart and lung, per milliliter plasma and erythrocytes of neonates. Ratios of PL-AA*- to TG-AA*derived $\mathrm{AA}^{*}$ incorporation were 0.95 in the heart and 1.7 in lung, plasma and erythrocytes. $(C$ and $D)$ Total dietary AA accretion from TG and PL sources, expressed as micrograms per day per whole heart and lung and per milliliter plasma and erythrocytes. Ratios of dietary TG-AA to PL-AA accretion in the heart, lung, plasma, and erythrocytes were $12.6,6.2,6.4$, and 6.4 , respectively. *Significant differences with $p \leq 0.05 . T G-A A^{*}$, neonates dosed with TG-AA* $(n=3) ; P L-A A^{*}$, neonates dosed with PL-AA* $(n=4)$.

$22: 4 n-6^{*}$ and $22: 5 n-6 *$ synthesis in neonate tissues. 22:4n-6* derived from TG-AA* and PL-AA* in liver, brain, retina, heart, and lung of baboon neonates is shown in Figure 3. In neonate brain and lung, recovery of tissue $22: 4 n-6^{*}$ from PL-AA* was 2-fold and 1.7-fold higher than TG-AA*-derived $22: 4 n-6 *$ respectively, which was close to the ratios of PL$\mathrm{AA}^{*}$ to TG-AA* derived brain and lung AA*.

22:5n-6* recovered in brain, retina, and liver were not different between TG-AA*- and PL-AA*-dosed neonates.

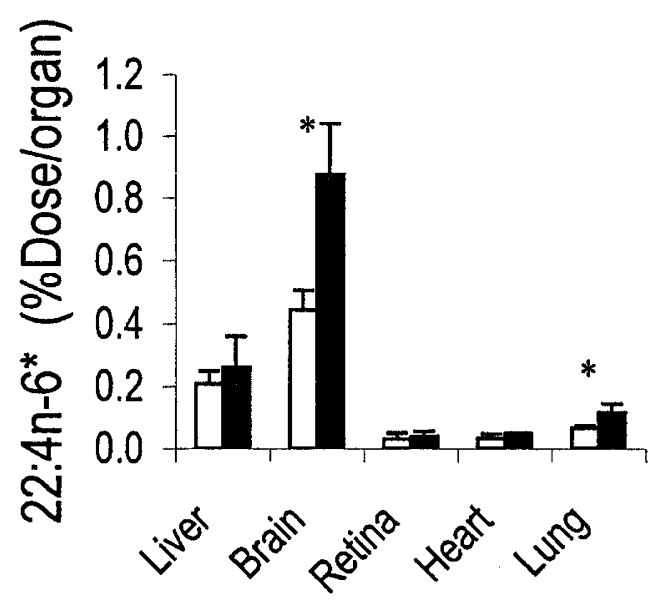

Figure 3. $22: 4 \mathrm{n}-6 *$ derived from TG (open bars) and PL (solid bars) sources of $\mathrm{AA}^{*}$, expressed as \%Dose, in whole liver, brain, retina, heart, and lung of neonates. In case of retina, $\%$ Dose $\times 10^{2}$ is reported. *Significant differences with $p \leq 0.05$. $T G-A A^{*}$, neonates dosed with TG-AA* $(n=3) ; P L-A A^{*}$, neonates dosed with PL-AA* $(n=4)$. 
About $0.15 \%, 0.0002 \%$, and $0.06 \%$ of $\mathrm{AA}^{*}$ doses were recovered as brain, retina, and liver $22: 5 n-6^{*}$ in the 4 -wk-old neonates, respectively.

\section{DISCUSSION}

This study is the first to determine the efficacy of dietary AA provided as a component of TG and PL as substrates for brain AA accretion in primate neonates. In the baboon neonate brain, accretion of AA provided as PL was 2.1-fold greater than TG source of AA, on a per mol basis measured at $10 \mathrm{~d}$ postdose. Accretion levels sampled at one time point using labeled tracers reflect overall integrated accretion levels if turnover of the metabolite is low. Because AA is the precursor for metabolites such as eicosanoids, AA turnover in all organs including brain is required. However, a previous study with fetal baboons (47) showed that 18:2-derived-AA continues to accumulate in fetal brain after $29 \mathrm{~d}$, indicating that brain AA accretion is much faster than turnover. Hence, in this study a single bolus dose of ${ }^{13} \mathrm{C}$-labeled $\mathrm{AA}^{*}$ in the sn-2 position of TG and PC were used as tracers to compare the two dietary lipid classes as sources of preformed AA for accretion in the brain and other organs of baboon neonates.

Brain is a primary target organ for AA and DHA accretion in human infants $(1,15)$. The accretion ratio of dietary AA provided as PL to TG, as \%Dose, was highest in brain compared with all the other neonatal organs in this study. Consistent with this observation, 22:4n-6 derived from PL-AA was higher than from TG-AA in the neonate brain, suggesting that PL-AA was the more active metabolic substrate.

Preferential incorporation and retention of PL-AA over TG-AA was also observed in the liver, lung, plasma, and erythrocytes of neonates, but the ratios of PL to TG AA accretion were smaller in these tissues than in the brain. The liver incorporated a slightly higher fraction of dose compared with brain, consistent with its major role in the uptake and primary metabolism of most fatty acids, including AA, in neonates when an adequate dietary supply of preformed AA is available (48).

Dietary AA accumulation expressed as absolute weight showed that formula TG-AA contributed to a greater extent than PL-AA to brain and other tissue AA in neonates. Total tissue AA accretion was greater from formula TG-AA because of the predominance of TG in the formula ( $92 \%$ formula AA in TG versus $8 \%$ in PL). We estimate that overall $2.3 \%, 0.002 \%$, and $3.2 \%$ of dietary AA was incorporated into brain, retina, and liver, respectively. Unlike most commercial infant formulas that do contain LCP, this formula is similar to human milk in its PL-bound LCP composition. These estimates are therefore likely to provide a better estimate for human milk values than, for instance, estimates derived for LCP-free formulas or formulas where LCP are exclusively in TG.

We can estimate the contribution of dietary preformed AA to postnatal brain AA accretion in term baboon neonates. The baboon brain weight is about $80 \mathrm{~g}$ at term gestation of $182 \mathrm{~d}$ (49). Brain AA concentration in the fetal baboon was about $1.37 \mathrm{mg} / \mathrm{g}$ wet weight (47), which was not correlated to gestational age. The mean total AA content of neonate brain at
4 wks of age was $172 \mathrm{mg}$. Hence, net accretion of AA during the 4-wk postnatal period is $62.4 \mathrm{mg}$. Neonates consumed an average of $44 \mathrm{mg} \mathrm{AA} / \mathrm{d}$. Our measurements indicate that $2.3 \%$ of formula AA appeared as brain AA. Thus, $28.8 \mathrm{mg}$ of formula AA accumulated as brain AA over the 4-wk period in the term neonate. This indicates that about 46\% (28.8/62.4) of postnatal brain AA was derived from dietary preformed AA in the 4-wk term baboon neonate. This calculation assumes that the incorporation of AA into brain has plateaued at $10 \mathrm{~d}$ postdose when the brain AA pool was sampled and that turnover of brain AA or output of AA from the brain is negligible. Although our measurements of 18:2-derived-AA fetal baboon kinetics demonstrate that AA plateaus out to $29 \mathrm{~d}$ after a single ${ }^{13} \mathrm{C}-18: 2$ dose (47), AA is an active substrate for several enzymes and undoubtedly turns over at a nonzero rate. Hence, the estimate derived from our calculations represents the minimum contribution of dietary preformed AA to brain AA accretion in baboon neonates.

Term and preterm neonates can synthesize LCP from their 18 carbon precursors $(21,50)$. Hence, formula 18:2n-6derived AA also contributes to brain AA accretion in neonates. However, the quantitative relationship of dietary $18: 2 n-6$ to brain AA accretion in primate neonates is not known. We can derive an estimate for maximal bioequivalence of dietary 18:2n-6 as a source of brain AA in primate infants based on our measurements. Dietary preformed AA contributed to $46 \%$ of brain $\mathrm{AA}$; if all the remaining brain $\mathrm{AA}$ was derived from formula $18: 2 n-6,54 \%$ of brain AA would be from dietary LA. Mean dietary LA consumed by the neonates was $1.1 \mathrm{~g} / \mathrm{d}$ or $31.5 \mathrm{~g}$ over the 4 -wk period. Maximal LA derived AA accumulation in brain was $0.034 \mathrm{~g}$. Hence the maximal percentage accretion of dietary LA as brain AA is only $0.11 \%(0.034 /$ $31.5)$. Thus, dietary preformed AA was 21 -fold $(2.3 / 0.11)$ more effective than dietary LA-derived AA as a substrate for brain AA accretion in 4-wk-old baboon neonates. However, in term neonates, brain AA could also have been derived from neonatal body stores, including liver LCP stores, which, along with adipose, have been shown to be important postnatal sources for brain LCP accretion in term infants (48). Thus, the estimated LA-derived AA accretion of $0.11 \%$ in brain represents the upper limit for LA conversion efficiency to brain AA. The bioequivalence of preformed AA as a substrate for brain AA compared with dietary LA derived AA is likely to be $>21$ in term primate neonates.

Dietary LCP concentrations, the ratio of n-6 to n-3 PUFA, and the ratio of dietary LCP enrichment in TG to PL are factors that all influence endogenous pool of fatty acids within tissues and thus the supply of AA to developing brain. Therefore, the accretion levels determined for dietary AA provided as TG and PL in this study apply strictly only to diets similar to the formula used in this study. However, the values for these factors used in this study are all within the range reported for human breast milk $(18,19)$ and therefore should provide physiologically relevant estimates of AA accretion.

The mechanisms underlying the preferential incorporation of dietary PL source of AA over TG source into neonate tissues remain to be investigated. Dietary PL is a minor source of PL presented to the gut at the time digestion and absorption, 
whereas bile-derived PL is reported to be the major source of intestinal PL (51). In this study, we included equal amounts of exogenous PC in both TG-AA* and PC-AA* doses to avoid any confounding effects of exogenous $\mathrm{PC}$ on intestinal assembly of lipoproteins and plasma PC content. Absorption of dietary AA provided as PL has been shown to be similar to breast milk AA, which is predominantly found as TG-AA (38, 39) and also similar to formula AA provided primarily as TG-AA (39). However, dietary source has been shown to alter the distribution of fatty acids into lipoproteins and lipid fractions (40). Lagarde et al. $(41,42)$ provided evidence that plasma lysoPC and nonesterified fatty acid fractions supplied PC derived DHA to erythrocytes, whereas lysoPC was the only major carrier of TG-DHA in human adults, suggesting higher bioavailability of PC-DHA for brain DHA accretion. Preferential incorporation of sn-2 lysoPC AA and DHA over nonesterified LCP into developing brain has been reported in rats (52). There are no published reports as to whether dietary AA carried by $\mathrm{PC}$ is preferentially incorporated into the $\mathrm{PC}$ fraction of lipoproteins, where HDL is the major carrier, or whether there is significant conversion of PC to unsaturated sn-2 lysoPC, to act as major carriers of LCP to primate neonate brain.

Another factor that may enhance accumulation of PC-AA into tissues is the prolonged retention of $\mathrm{PC}$-derived $\mathrm{AA}$ in the plasma compared with TG-derived AA. This is consistent with the finding of higher PC-AA in plasma than TG-AA even after $10 \mathrm{~d}$ postdosing in the baboon neonates. Prolonged retention of dilinoleoyl PC in the plasma of human adults has been reported (53). Further, recycling of LA, LNA, and DHA for de novo lipogenesis in neural tissues has been shown to be a major pathway in neonates $(54,55)$. The extent to which $\mathrm{AA}$ is recycled in primate neonates, and role of dietary lipid class in AA recycling, remain open questions.

The practical significance of this study is that it provides evidence that dietary PL-derived AA when included at breast milk levels in formulas is a more efficient carrier for primate brain AA accretion, compared with TG as a carrier of AA. This is particularly relevant in the case of preterm infants, who are born with low stores of n- 6 and n-3 LCP $(56,57)$. Our measurements suggest that formulas with LCP carried by PL may be more effective for brain LCP accretion compared with formulas that provide LCP as TG only.

In conclusion, this study showed a 2.1 -fold preferential incorporation and retention of dietary PL-derived AA over TG-derived AA in developing brain of primate neonates. Overall, $2.3 \%, 0.002 \%$, and $3.2 \%$ of dietary AA was found in brain, retina, and liver, respectively, in term baboon neonates consuming a formula with LCP and lipid class composition similar to human breast milk. Dietary preformed AA was at least 21-fold more effective than dietary LA-derived AA as a substrate for brain AA accretion. Dietary AA accounted for about $46 \%$ of brain AA accumulated in 4-wk-old term neonates, emphasizing the importance of dietary preformed AA supply for postnatal brain AA accretion in term primate infants.

Acknowledgments. We thank Stefan Ley, Gerard Moine, and August Rüttimann for the chemical synthesis of the tracer molecules.

\section{REFERENCES}

1. Martinez M 1992 Tissue levels of polyunsaturated fatty acids during early human development. J Pediatr 120:S129-S138

2. Uauy R, Mena P, Rojas C 2000 Essential fatty acids in early life: structural and functional role. Proc Nutr Soc 59:3-15

3. King ME, Stavens BW, Spector AA 1977 Diet-induced changes in plasma membrane fatty acid composition affect physical properties detected with a spin-label probe. Biochemistry 16:5280-5285

4. Slater SJ, Kelly MB, Taddeo FJ, Ho C, Rubin E, Stubbs CD 1994 The modulation of protein kinase C activity by membrane lipid bilayer structure. J Biol Chem 269:48664871

5. Danesch U, Weber PC, Sellmayer A 1996 Differential effects of n-6 and n-3 polyunsaturated fatty acids on cell growth and early gene expression in Swiss 3T3 fibroblasts. J Cell Physiol 168:618-624

6. Sellmayer A, Danesch U, Weber PC 1996 Effects of different polyunsaturated fatty acids on growth-related early gene expression and cell growth. Lipids 31(suppl):S37S40

7. Piomelli D, Volterra A, Dale N, Siegelbaum SA, Kandel ER, Schwartz JH, Belardetti F 1987 Lipoxygenase metabolites of arachidonic acid as second messengers for presynaptic inhibition of aplysia sensory cells. Nature 328:38-43

8. Katsuki H, Okuda S 1995 Arachidonic acid as a neurotoxic and neurotrophic substance. Prog Neurobiol 46:607-636

9. Koletzko B, Braun M 1991 Arachidonic acid and early human growth: is there a relation? Ann Nutr Metab 35:128-131

10. Carlson SE, Werkman SH, Peeples JM, Cooke RJ, Tolley EA 1993 Arachidonic acid status correlates with first year growth in preterm infants. Proc Natl Acad Sci U S A 90:1073-1077

11. Jensen CL, Prager TC, Fraley JK, Chen H, Anderson RE, Heird WC 1997 Effect of dietary linoleic/alpha-linolenic acid ratio on growth and visual function of term infants J Pediatr 131:200-209

12. Woltil HA, van Beusekom CM, Schaafsma A, Muskiet FA, Okken A 1998 Longchain polyunsaturated fatty acid status and early growth of low birth weight infants. Eur J Pediatr 157:146-152

13. O'Brien JS, Sampson EL 1965 Fatty acid and fatty aldehyde composition of the major brain lipids in normal human gray matter, white matter, and myelin. J Lipid Res 6:545-551

14. Martinez M, Mougan I 1998 Fatty acid composition of human brain phospholipids during normal development. J Neurochem 71:2528-2533

15. Sinclair AJ, Crawford MA 1972 The accumulation of arachidonate and docosahexaenoate in the developing rat brain. J Neurochem 19:1753-1758

16. Dobbing J, Sands J 1973 Quantitative growth and development of human brain. Arch Dis Child 48:757-767

17. Dobbing J, Sands J 1979 Comparative aspects of the brain growth spurt. Early Hum Dev 3:79-83

18. Innis SM 1992 Human milk and formula fatty acids. J Pediatr 120:S56-S61

19. Jensen RG 1996 The lipids in human milk. Prog Lipid Res 35:53-92

20. Carnielli VP, Wattimena DJ, Luijendijk IH, Boerlage A, Degenhart HJ, Sauer PJ 1996 The very low birth weight premature infant is capable of synthesizing arachidonic and docosahexaenoic acids from linoleic and linolenic acids. Pediatr Res 40:169-174

21. Salem Jr N, Wegher B, Mena P, Uauy R 1996 Arachidonic and docosahexaenoic acids are biosynthesized from their 18-carbon precursors in human infants. Proc Natl Acad Sci U S A 93:49-54

22. Makrides M, Neumann MA, Byard RW, Simmer K, Gibson RA 1994 Fatty acid composition of brain, retina, and erythrocytes in breast- and formula-fed infants. Am J Clin Nutr 60:189-194

23. Cunnane SC, Francescutti V, Brenna JT, Crawford MA 2000 Breast-fed infants achieve a higher rate of brain and whole body docosahexaenoate accumulation than formula-fed infants not consuming dietary docosahexaenoate. Lipids 35:105-111

24. Uauy R, Hoffman DR 2000 Essential fat requirements of preterm infants. Am J Clin Nutr $71: 245 \mathrm{~S}-250 \mathrm{~S}$

25. Lauritzen L, Hansen HS, Jorgensen MH, Michaelsen KF 2001 The essentiality of long chain n-3 fatty acids in relation to development and function of the brain and retina. Prog Lipid Res 40:1-94

26. Carlson SE, Cooke RJ, Rhodes PG, Peeples JM, Werkman SH 1992 Effect of vegetable and marine oils in preterm infant formulas on blood arachidonic and docosahexaenoic acids. J Pediatr 120:S159-S167

27. Farquharson J, Cockburn F, Patrick WA, Jamieson EC, Logan RW 1992 Infant cerebral cortex phospholipid fatty-acid composition and diet [see comments]. Lancet 340:810-813

28. Hoffman DR, Birch EE, Birch DG, Uauy R, Castaneda YS, Lapus MG, Wheaton DH 2000 Impact of early dietary intake and blood lipid composition of long-chain polyunsaturated fatty acids on later visual development. J Pediatr Gastroenterol Nutr 31:540-53

29. Innis SM 2000 Essential fatty acids in infant nutrition: lessons and limitations from animal studies in relation to studies on infant fatty acid requirements. Am J Clin Nutr $71: 238 \mathrm{~S}-244 \mathrm{~S}$

30. Carnielli VP, Luijendijk IH, van Beek RH, Boerma GJ, Degenhart HJ, Sauer PJ 1995 Effect of dietary triacylglycerol fatty acid positional distribution on plasma lipid classes and their fatty acid composition in preterm infants. Am J Clin Nutr 62:776-781

31. Nelson CM, Innis SM 1999 Plasma lipoprotein fatty acids are altered by the positional distribution of fatty acids in infant formula triacylglycerols and human milk. Am J Clin Nutr 70:62-69

32. Greiner RC, Winter J, Nathanielsz PW, Brenna JT 1997 Brain docosahexaenoate accretion in fetal baboons: bioequivalence of dietary alpha-linolenic and docosahexaenoic acids. Pediatr Res 42:826-834 
33. Su HM, Bernardo L, Mirmiran M, Ma XH, Corso TN, Nathanielsz PW, Brenna JT 1999 Bioequivalence of dietary alpha-linolenic and docosahexaenoic acids as sources of docosahexaenoate accretion in brain and associated organs of neonatal baboons. Pediatr Res 45:87-93

34. Abedin L, Lien EL, Vingrys AJ, Sinclair AJ 1999 The effects of dietary alphalinolenic acid compared with docosahexaenoic acid on brain, retina, liver, and heart in the guinea pig. Lipids 34:475-482

35. Fu Z, Sinclair AJ 2000 Increased alpha-linolenic acid intake increases tissue alphalinolenic acid content and apparent oxidation with little effect on tissue docosahexaenoic acid in the guinea pig. Lipids 35:395-400

36. Su HM, Keswick LA, Brenna JT 1996 Increasing dietary linoleic acid in young rats increases and then decreases docosahexaenoic acid in retina but not in brain. Lipids 31:1289-1298

37. Jensen RG 1989 Lipids in Human Milk - Composition and Fat Soluble Vitamins, 2nd Ed. New York, Raven, pp 57-59

38. Boehm G, Muller H, Kohn G, Moro G, Minoli I, Bohles HJ 1997 Docosahexaenoic and arachidonic acid absorption in preterm infants fed LCP-free or LCPsupplemented formula in comparison to infants fed fortified breast milk. Ann Nutr Metab 41:235-241

39. Carnielli VP, Verlato G, Pederzini F, Luijendijk I, Boerlage A, Pedrotti D, Sauer PJ 1998 Intestinal absorption of long-chain polyunsaturated fatty acids in preterm infants fed breast milk or formula. Am J Clin Nutr 67:97-103

40. Tso P, Drake DS, Black DD, Sabesin SM 1984 Evidence for separate pathways of chylomicron and very low-density lipoprotein assembly and transport by rat small intestine. Am J Physiol 247:G599-G610

41. Brossard N, Croset M, Normand S, Pousin J, Lecerf J, Laville M, Tayot JL, Lagarde M 1997 Human plasma albumin transports [13C]docosahexaenoic acid in two lipid forms to blood cells. J Lipid Res 38:1571-1582

42. Lemaitre-Delaunay D, Pachiaudi C, Laville M, Pousin J, Armstrong M, Lagarde M 1999 Blood compartmental metabolism of docosahexaenoic acid (DHA) in humans after ingestion of a single dose of [(13)C]DHA in phosphatidylcholine. J Lipid Res 40:1867-1874

43. Boehm G, Borte M, Bohles HJ, Muller H, Kohn G, Moro G 1996 Docosahexaenoic and arachidonic acid content of serum and red blood cell membrane phospholipids of preterm infants fed breast milk, standard formula or formula supplemented with n-3 and n-6 long-chain polyunsaturated fatty acids. Eur J Pediatr 155:410-416

44. Bligh E, Dyer W 1959 A rapid method of total lipid extraction and purification. Can J Biochem Physiol 37:911-917
45. Brenna JT, Corso TN, Tobias HJ, Caimi RJ 1997 High-precision continuous-flow isotope ratio mass spectrometry. Mass Spectrom Rev 16:227-258

46. Clandinin MT, Chappell JE, Leong S, Heim T, Swyer PR, Chance GW 1980 Extrauterine fatty acid accretion in infant brain: implications for fatty acid requirements. Early Hum Dev 4:131-138

47. Su HM, Corso TN, Nathanielsz PW, Brenna JT 1999 Linoleic acid kinetics and conversion to arachidonic acid in the pregnant and fetal baboon. J Lipid Res 40:1304-1312

48. Clandinin MT, Chappell JE, Heim T, Swyer PR, Chance GW 1981 Fatty acid accretion in fetal and neonatal liver: implications for fatty acid requirements. Early Hum Dev 5:7-14

49. Hendrickx A 1971 Embryology of the Baboon. University of Chicago Press, Chicago

50. Demmelmair H, von Schenck U, Behrendt E, Sauerwald T, Koletzko B 1995 Estimation of arachidonic acid synthesis in full term neonates using natural variation of 13C content. J Pediatr Gastroenterol Nutr 21:31-6

51. Akesson B 1982 Content of phospholipids in human diets studied by the duplicateportion technique. Br J Nutr 47:223-229

52. Thies F, Pillon C, Moliere P, Lagarde M, Lecerf J 1994 Preferential incorporation of sn-2 lysoPC DHA over unesterified DHA in the young rat brain. Am J Physiol 267:R1273-R1279

53. Galli C, Sirtori CR, Mosconi C, Medini L, Gianfranceschi G, Vaccarino V, Scolastico C 1992 Prolonged retention of doubly labeled phosphatidylcholine in human plasma and erythrocytes after oral administration. Lipids 27:1005-1012

54. Sheaff Greiner RC, Zhang Q, Goodman KJ, Giussani DA, Nathanielsz PW, Brenna JT 1996 Linoleate, alpha-linolenate, and docosahexaenoate recycling into saturated and monounsaturated fatty acids is a major pathway in pregnant or lactating adults and fetal or infant rhesus monkeys. J Lipid Res 37:2675-2686

55. Cunnane SC, Menard CR, Likhodii SS, Brenna JT, Crawford MA 1999 Carbon recycling into de novo lipogenesis is a major pathway in neonatal metabolism of linoleate and alpha-linoleate. Prostaglandins Leukot Essent Fatty Acids 60:387392

56. Martinez M 1991 Developmental profiles of polyunsaturated fatty acids in the brain of normal infants and patients with peroxisomal diseases: severe deficiency of docosahexaenoic acid in Zellweger's and pseudo- Zellweger's syndromes. World Rev Nutr Diet 66:87-102

57. Crawford M 2000 Placental delivery of arachidonic and docosahexaenoic acids: implications for the lipid nutrition of preterm infants. Am J Clin Nutr 71:275S$284 \mathrm{~S}$ 